\title{
A Cross-Sectional Study on Gender Differences and Influence of Social Media Engagement on Breast Cancer Knowledge among Delhi-NCR Population in India
}

\author{
Nibha Sinha1, Alka Sharma²
}

${ }^{1}$ Ph.d Scholar, Department of Humanities and Social Sciences, Jaypee Institute of Information and Technology, A10, Sector-62, Noida, (India), Pin-201309; ${ }^{2}$ Dean, Department of Humanities and Social Sciences, Jaypee Institute of Information and Technology, A-10, Sector-62, Noida, (India), Pin-201309

\begin{tabular}{|c|c|c|c|c|c|c|c|}
\hline Abstract & Introduction & Methodology & Results & Conclusion & References & Citation & Tables / Figures \\
\hline \multicolumn{8}{|c|}{ Corresponding Author } \\
\hline \multicolumn{7}{|c|}{$\begin{array}{l}\text { Nibha Sinha, J-3109, Gaur Green City, 8, Vaibhav Khand, Indirapuram, Ghaziabad (Uttar Pradesh) } \\
\text { India, Pin-201014 } \\
\text { E Mail ID: sinha nibha@yahoo.com }\end{array}$} & 回部回 \\
\hline
\end{tabular}

\section{Citation}

Sinha N, Sharma A. A Cross-Sectional Study on Gender Differences and Influence of Social Media Engagement on Breast Cancer Knowledge among Delhi-NCR Population in India.Indian J Comm Health. 2021;33(1):198-201. https://doi.org/10.47203/IJCH.2021.v33i01.028

Source of Funding: Nil Conflict of Interest: None declared

\section{Article Cycle}

Received: 14/01/2021; Revision: 25/01/2021; Accepted:18/02/2021; Published:31/03/2021

This work is licensed under a Creative Commons Attribution 4.0 International License.

\section{Abstract}

Breast cancer is leading cause of death worldwide including India. Low awareness is one factor causing late diagnosis and eventually death in developing countries like India. Social media is being used for breast cancer awareness. This study aimed to investigate relationship between social media engagement and breast cancer knowledge and to examine gender differences. Cross sectional study was conducted in Delhi-National Capital Region (NCR). Pearson's coefficient correlation test was conducted to examine social media engagement and breast cancer knowledge relationship. Independent t test was applied to find gender differences for social media engagement and breast cancer knowledge. Significant moderate correlation was found between social media engagement and breast cancer knowledge ( $p<.01)$. A gender difference was found for social media engagement and breast cancer knowledge $(p<.05)$. Result justified that social media engagement is resulting in breast cancer awareness. Results also confirmed difference between male and female regarding social media engagement and breast cancer knowledge.

\section{Keywords}

Breast Cancer; Social Media; Awareness; Gender Differences.

\section{Introduction}

Breast cancer is a global burden (1) and it is the most common cancer among women of India.(2) Poor level of awareness of the disease is one factor among others causing advance diagnosis and eventually death $(2,3)$ especially in developing countries like India. Because this disease is more prevalent among women than men; (4) so, in India, mostly efforts have been made for women awareness and evaluate their knowledge, attitude and practices. $(3,5)$ After the advent of internet, social media is being widely used to promote breast cancer awareness. (6) In recent times, this media has become popular in India across the gender. (7)

In authors' knowledge, no study has attempted so far to understand the influence of social media engagement on the awareness level of breast cancer of women as well as men in Delhi-National Capital Region (NCR) of India. We also tried to look into the 
gender difference in social media engagement and knowledge level of breast cancer.

\section{Aims \& Objectives}

1. To investigate the relationship between social media engagement and breast cancer awareness across the gender.

2. To examine the gender difference in social media engagement and breast cancer awareness.

\section{Material \& Methods}

Data Collection: We conducted face to face crosssectional questionnaire survey in Delhi-NCR of India from June 2019 to February 2020. Selection criteria included both males and females using social media, 20 to 65 years of age. Individuals were excluded if they were having any history of breast cancer. 382 fully filled up questionnaire were analyzed.

Sample Selection Procedure: In the absence of population frame, the calculated sample size was 385 assuming that about $50 \%$ social media users in Delhi-NCR of India lack knowledge about breast cancer with margin error of $\pm 5 \%$ and confidence level of $95 \%$. After adding $5 \%$ of non-responses, it turned out to be 405 . We used purposive sampling method; type of non-probability sampling.

Study Instrument: A questionnaire adapted from previous literature $(5,8,9)$ suitable in Indian context was developed on seven point Likert scale. Part one had questions about demographic details. Part two consisted eight items related to social media engagement. Part three consisted of three subscales and 19 items in all. First sub- scale had seven items related to modifiable risk factors of breast cancer, second sub-scale had eight questions on symptoms and third sub- scale had four questions related to screening knowledge. To measure the internal consistency of the scale Cronbach alpha value was computed. For social media engagement scale, Cronbach alpha value was .79. For breast cancer scale, Cronbach alpha was .91 was for all 19 items. For all three sub-scales alpha values were respectively found to be $.94, .92$ and .86 , that is as per required value. Correlation coefficient was used to measure construct validity of the scale ranging from .310 to .569 for social media engagement scale and .363 to .890 for breast cancer scale, indicating a moderate to very good positive and statistically significant relationship among all items of both the scale. On a seven-point scale, minimum score was eight and maximum was 56 points for social media engagement and 19 minimum and 133 maximum points for breast cancer awareness.

Statistical Analysis: In this study, social media engagement is independent variable and breast cancer knowledge is dependent variable. Data analysis was done in SPSS version-21. Data normality test was conducted using Kolmogorov-Smirnov test. Data was normally distributed so, Pearson's coefficient correlation test was conducted to test the relationship between social media engagement and breast cancer knowledge. Further, independent sample $t$ test was conducted to examine the differences between male and female social media engagement and breast cancer knowledge. A p-value $<0.05$ was considered significant for all the analysis. Ethical Approval: Approval was not required from the ethical committee because study was conducted without any human intervention. Consent was taken from all the participants and their confidential concerns were maintained.

\section{Results}

Of all the respondents ( $n=382), 43.7 \%(n=167)$ were male and $56.3 \%(n=215)$ were female. Overall mean age of the respondents was $36.47 \pm 8.89$ years. In all, maximum $67.3 \%(n=257)$ participants were graduate and $26.7 \%(n=102)$ were post graduate. Only $6 \%$ $(n=23)$ respondents were intermediate. $31.2 \%$ $(n=119)$ were homemaker, $65.2 \%(n=249)$ were in service and $3.7 \% \quad(n=14)$ were student. Large percentage of the respondents; $87 \%(n=317)$ were married, $15.4 \%$ were single and only $1.6 \%(n=6)$ were in other category. Maximum $87.8 \%$ participants confirmed that their source of breast cancer knowledge is social media.

Significant moderate correlation found between social media engagement and breast cancer awareness $(p<.01)$ for all the respondents. Both male and female separately too had significant medium relationship between their social media engagement and breast cancer awareness. All details are given in (Table-1).

There was statistically significant gender differences found between male and female sample population for social media engagement and breast cancer knowledge as well. All details are given in (Table-2).

\section{Discussion}

In authors' knowledge, previous studies have been conducted to understand the association of sociodemographic factors with breast cancer awareness. $(1,5)$ This is the first attempt to evaluate the 
association of social media engagement with breast cancer knowledge of women as well as men. Additionally, gender differences were also studied for social media engagement and breast cancer knowledge. Given the fact that social media is now popular tool to reach people for breast health education and its popularity among all the demographics, this study result will be very useful to understand how much this media is associated with breast cancer knowledge among women as well as men.

This study has mainly three findings. First; there were statistically significant moderate correlation between social media engagement and breast cancer awareness across the gender. Second, there were more pronounced relationship between independent and dependent variables in women than men. Third; female participants had statistically significant higher mean values for social media engagement and breast cancer awareness than men. The finding that there is significant relationship between social media engagement and breast cancer awareness are consistent with earlier studies where social networking sites were found effective for health behavior related outcomes. (10) Our study result that women were having good awareness about breast cancer is in contrast with earlier studies where women were having poor awareness about breast cancer. (3) In these studies, it was not revealed whether women were using social media and what was their source of breast cancer knowledge. So, here it can be claimed that social media is generating knowledge about breast cancer among women. Men were having less knowledge about breast cancer than women that is consistent with earlier study. (1) This difference may also be due to the fact that breast cancer is not affecting men directly so much, (4) so they would have shown less interest in breast cancer information available on social media.

Furthermore, this study finding suggests that a very good percentage of the participants were married $(87 \%)$ that might have resulted in higher knowledge of breast cancer coming through social media. This may have happened due to the fact that marriage affects opinion and requirements of the partners. Also better awareness of breast cancer may have come through social media because a majority percentage of the participants were having good educational background. Additionally, a quite good percentage of the participants $(65.2 \%)$ were in service, which might be one reason that their network was good on social media and getting good knowledge about breast cancer. In our study, about $79.8 \%$ of the participants have confirmed that their source of breast cancer knowledge was social media, which is constant with earlier findings. (8)

\section{Conclusion}

This study result found significant association between social media engagement and breast cancer knowledge across the gender. Gender differences for social media engagement and breast cancer awareness were also found between male and female.

\section{Recommendation}

If government, health professionals and allied organizations take proactive approach to use social media to make people aware through their authentic and validated knowledge about breast cancer, late diagnosis and increasing mortality rate can be curbed to a great extent.

\section{Limitation of the study}

In spite of some captivating findings, we have some limitations too in our study. Firstly, our sample was selected from Delhi-NCR of India, so it cannot be generalized to the total population of India. Secondly, we used purposive sampling method which might have caused unequal representation of the study population. Further studies should consider intervention based study and also focus small towns and rural areas.

\section{Relevance of the study}

Despite various attempts of governments using other media awareness target was not achieved. Our study results would help government and health professionals and allied organizations to incorporate social media as health awareness tool on priority basis.

\section{Authors Contribution}

All authors have contributed equally.

\section{Acknowledgement}

We would like to extend our gratitude to all the participants for their co-operation.

\section{References}

1. Oswal K, Kanodia R, Pradhan A, Nadkar U, Avhad M, Venkataramanan R, Sethuraman L, Caduff C, Purushotham A. Assessment of Knowledge and Screening in Oral, Breast, and Cervical Cancer in the Population of the Northeast Region of India. JCO Glob Oncol. 2020;6:601-609. doi: 
INDIAN JOURNAL OF COMMUNITY HEALTH / VOL 33 / ISSUE NO 01 / JAN-MAR2021 10.1200/JGO.19.00257. PMID: 32302235; PMCID: PMC7193798.[PubMed]

2. Suhani, Oberoi AS. Instagram or mammogram: What are Indian women more aware of? Indian J Cancer. 2020;57(4):498-499. doi: 10.4103/ijc.IJC_555_19. PMID: 32594070. [PubMed]

3. Gupta A, Shridhar K, Dhillon PK. A review of breast cancer awareness among women in India: Cancer literate or awareness deficit? Eur J Cancer. 2015;51(14):2058-66. doi: 10.1016/j.ejca.2015.07.008. Epub 2015 Jul 29. PMID: 26232859; PMCID: PMC4571924.[PubMed]

4. Chikaraddi SB, Krishnappa R, Deshmane V. Male breast cancer in Indian patients: is it the same? Indian J Cancer. 2012;49(3):272-6. doi: 10.4103/0019-509X.104484. PMID: 23238143. [PubMed]

5. Singh S, Pal A, Srivastava NK, Thakur P. Level of Awareness and Practices of Women Regarding Breast Cancer in Chhattisgarh, India: An Institution Based Survey. Int J Med Public Heal 2018;8(4):145-51.

6. Mansour D, Nashwan A, Abu Rasheed H, Hararah M, Nassar $\mathrm{H}$, Abu Abbas R, et al. Use of Social Media in Breast Cancer Awareness: GCC Countries' Experience. J Glob Oncol 2018;4(Supplement 2):30s-30s.
[Breast Cancer Knowledge...] | Nibha S et al

7. Social media usage in India - statistics \& facts | Statista Available

https://www.statista.com/topics/5113/social-mediausage-in-india/\#professional [accessed on 18 Feb 2021]

8. Rahman SA, Al-Marzouki A, Otim M, Khalil Khayat NEH, Yousuf R, Rahman P. Awareness about Breast Cancer and Breast Self-Examination among Female Students at the University of Sharjah: A Cross-Sectional Study. Asian Pac J Cancer Prev. 2019;20(6):1901-1908. doi: 10.31557/APJCP.2019.20.6.1901. PMID: 31244316; PMCID: PMC7021607.[PubMed].

9. Rosen LD, Whaling K, Carrier LM, Cheever NA, Rokkum J. The Media and Technology Usage and Attitudes Scale: An empirical investigation. Comput Human Behav. 2013;29(6):2501-2511. doi: 10.1016/j.chb.2013.06.006. PMID: 25722534; PMCID: PMC4338964.[PubMed]

10. Laranjo L, Arguel A, Neves AL, Gallagher AM, Kaplan R, Mortimer N, Mendes GA, Lau AY. The influence of social networking sites on health behavior change: a systematic review and meta-analysis. J Am Med Inform Assoc. 2015;22(1):243-56. doi: 10.1136/amiajnl-2014-002841. Epub 2014 Jul 8. PMID: 25005606; PMCID: PMC4433372.[PubMed].

\section{Tables}

TABLE 1 PEARSON CORRELATION BETWEEN SOCIAL MEDIA ENGAGEMENT AND BREAST CANCER AWARENESS

\begin{tabular}{|l|l|l|}
\hline Correlation of Social media engagement with & Pearson Correlation coefficient, $r$ & $.000^{* *}$ \\
\hline Breast cancer knowledge (of all) & .479 & $.000^{* *}$ \\
\hline Male & .331 & $.000^{*}$ \\
\hline Female & .473 & $.00 *^{*}$ \\
\hline Risk factors of breast cancer (of all) & .343 & $.00 *^{*}$ \\
\hline Male & .313 & $.000^{*}$ \\
\hline Female & .398 & $.000^{* *}$ \\
\hline Symptoms of breast cancer (of all) & .360 & $.000^{*}$ \\
\hline Male & .317 & $.000^{*}$ \\
\hline Female & .327 & $.000^{* *}$ \\
\hline Screening methods of breast cancer (of all) & .433 & $.00 *^{* *}$ \\
\hline Male & .385 & $.000^{* *}$ \\
\hline Female & .325 & \\
\hline$*$ correlation is significant at the 0.05 level (two-tailed); **orrelation is significant at the 0.01 level (two-tailed) \\
\hline
\end{tabular}

TABLE 2 MEAN VALUES OF SOCIAL MEDIA ENGAGEMENT (SME) AND BREAST CANCER AWARENESS (BCA) OF MALE AND FEMALE

\begin{tabular}{|c|c|c|c|c|c|}
\hline Parameter & $\begin{array}{l}\text { Male( }(n=167) \\
\text { Mean } \pm \text { sd }\end{array}$ & $\begin{array}{l}\text { Female }(n=215) \\
\text { Mean } \pm \text { sd }\end{array}$ & Mean difference $(95 \% \mathrm{Cl})$ & t statistics(df) & $\begin{array}{l}\text { p- } \\
\text { value* }\end{array}$ \\
\hline Age & $34.45 \pm 9.28$ & $38.03 \pm 8.26$ & $3.58(-5.37$ to -1.78$)$ & $-3.921(334.76)$ & $<.001$ \\
\hline SME & $32.80 \pm 7.18$ & $39.25 \pm 6.71$ & $6.44(-7.86$ to -5.03$)$ & $-8.95(344.65)$ & $<.001$ \\
\hline BCA & $70.49 \pm 13.73$ & $102.68 \pm 8.64$ & 26.489(-34.58to 29.79) & $-26.483(264.42)$ & $<.001$ \\
\hline Risk factors knowledge & $23.17 \pm 8.75$ & $37.74 \pm 6.14$ & 14.56(-16.13to -12.99) & $-18.27(285.05)$ & $<.001$ \\
\hline Symptoms knowledge & $30.13 \pm 9.88$ & $43.86 \pm 6.48$ & 13.68(-15.42to 11.94$)$ & $-15.48(271.89)$ & $<.001$ \\
\hline Screening knowledge & $17.14 \pm 4.76$ & $21.08 \pm 3.52$ & $-3.94(-4.80$ to -3.07$)$ & $-8.94(295.77)$ & $<.001$ \\
\hline
\end{tabular}

